\title{
China Eco-Wisdom: A Review of Sustainability of Agricultural Heritage Systems on Aquatic-Ecological Conservation
}

\author{
Maolin $\mathrm{Li}^{1,2}$, Yongxun Zhang ${ }^{3, *} \mathbb{C}$, Ming $\mathrm{Xu}^{4, *}$, Lulu He ${ }^{5}$, Longteng Liu ${ }^{6}$ and Qisheng Tang ${ }^{7}$ \\ 1 College of Forestry, Xinyang Agriculture and Forestry University, Xinyang 464000, China; \\ limaolin99@hotmail.com \\ 2 Bureau of Ecology and Environment, The Third Division of Xinjiang Production and Construction Corps, \\ Tumushuke 844000, China \\ 3 Institute of Agricultural Economics and Development, Chinese Academy of Agricultural Sciences, \\ Beijing 100081, China \\ 4 Center of International Cooperation Service, Ministry of Agriculture and Rural Affair, Beijing 100125, China \\ 5 College of Humanities and Development Studies, China Agricultural University, Beijing 100094, China; \\ helulu2013@163.com \\ 6 Fisheries Development Strategy Research Center, Chinese Academy of Fishery Sciences, Beijing 100141, \\ China; liult@cafs.ac.cn \\ 7 Yellow Sea Fisheries Research Institute, Chinese Academy of Fishery Sciences, Qingdao 266071, China; \\ ysfri.chn@gmail.com \\ * Correspondence: zhangyongxun@caas.cn (Y.Z.); xuming@agri.gov.cn (M.X.); Tel.: +86-010-8210-6193 (Y.Z.)
}

Received: 11 October 2019; Accepted: 15 December 2019; Published: 19 December 2019

\begin{abstract}
The multiple problems of modern agriculture urge people to probe into sustainability of the traditional agriculture. As important representatives of Chinese traditional agriculture, the agricultural heritage systems on aquatic-ecological conservation (AHSAEC) are confronting threats and urgently needs to be protected. In this study, the functions and value of the AHSAECs are analyzed by multi-disciplinary methods including system analysis methods based on the review of old books and modern scientific research literature, and the nature of their sustainability are discussed, and the countermeasures against their current unsustainability are proposed. The results show that AHSAECs derive from the simple eco-agriculture models such as the Taihu Lake multi-industry compound ecoagriculture model in historical periods. These systems can integrate farming, forestry, animal husbandry, and aquaculture and make them a sustainable recycling system. Thus, they have strong ecological stability, rich cultural connotation, and good comprehensive benefits. Traditional eco-wisdom from Chinese traditional culture is the power to promote the sustainability and high-quality development of these systems. The key eco-wisdom of AHSAECs is to integrate aquaculture with livestock and poultry breeding and planting through the harmless treatment and recycling of agricultural wastes, which is conducive to the aquatic ecosystem conservation and sustainable resources utilization. Nowadays, it is urgent to preserve the eco-wisdom by establishing ecological museums to realize the productive protection and inheriting development of the heritage systems.
\end{abstract}

Keywords: agricultural heritage system; eco-wisdom; aquatic ecosystem conservation; China

\section{Introduction}

Nowadays, human pressures are increasing global environmental risks and constitute the most important driver of planetary change [1]. Agriculture is the largest driver of global environmental 
change [2]. Thus, it is necessary to carry forward sustainable intensification of agriculture for human prosperity and global sustainability [3]. 2030 Agenda for Sustainable Development of UN put forward that eradicating hunger and food insecurity and ensuring sustainability of agriculture and natural resource management are central pillars of the global Sustainable Development Goals (SDGs) [4]. However, more than 0.82 billion people are still hungry in 2019. The world is not on track for meeting major SDG targets related to sustainable agriculture, food security, and nutrition [5]. Therefore, how to achieve a high yield and sustainability of agriculture on the premise of reducing environmental negative effects and ensuring ecological balance is a challenge for people all over the world. For developing countries like China, the ability of developing sustainable agriculture is decisive for national development.

With the rapid development of modern agriculture, China is also facing a series of agricultural problems, for example, arable land resource reduction, excessive consumption of energy, water, and nutrients, pressure from climate change, loss of germplasm resources, soil erosion, and environmental pollution [6-9]. However, studies have shown that the existing traditional agricultural methods in different areas have unique advantages in adapting to climate change, providing ecosystem services, protecting the environment, and so on $[10,11]$. Therefore, people began to rethink the policies, modes, and technologies of agricultural development and to pay attention to the redevelopment of traditional agricultural value [12]. China is one of the important origin centers of world agriculture. In the long history, all ethnic groups have gradually created various stable, sustainable, and efficient land use systems based on the local physical and geographical conditions. These systems have outstanding peculiarities and highly unified economic and ecological values under the co-evolution and dynamic adaptation of man and nature. They present the comprehensive features of natural heritage, cultural heritage, and intangible cultural heritage, as well as the unique idea of dynamic ecosystem conservation and sustainable agricultural development [13]. Since the concept of globally important agricultural heritage system (GIAHS) (in 2002, GIAHS was initiated by FAO for protecting those outstanding sustainable traditional agricultural systems around the world from destruction of high chemical fertilizers and pesticides and herbicides. GIAHS is defined by FAO as "Remarkable land use systems and landscapes which are rich in globally significant biological diversity evolving from the co-adaptation of a community with its environment and its needs and aspirations for sustainable development". Becoming a GIAHS, a traditional agricultural system needs to meet five criteria, which are to have food and livelihood security, biodiversity and ecosystem function, knowledge systems and adapted technologies, culture, value systems, and social organizations (Agriculture), and remarkable landscapes, land and water resources management features [14]) was put forward by FAO in 2002, China had begun to carry out a large-scale and systematic work on the exploration and protection of agricultural heritage systems (AHS) to protect the abovementioned land use systems [12]. For example, Ministry of Agriculture of the P.R.C. launched China NIAHS (China, South Korea, and Japan have initiated nationally important agricultural heritage systems (NIAHS) in 2012, 2012, and 2016 according to the NIAHS selection criteria that is based on GIAHS criteria. At present, China has designated four batches and sums 91 China NIAHS. South Korea has designated nine Korea NIAHS and five Korea important fishery heritage systems (KIFHS). Japan has designated eight Japan IAHSs) protection project in 2012. At present, a lot of research and work has focused on understanding and exploring the sustainability of AHS. In ecological sustainability, the sustainable mechanism of various AHSs has been explored by researchers such as rice-fish coculture system [15], rice-fish-duck coculture in paddy fields [16], the resilience of rice terraces to extreme climate [17], and interaction mechanism between jujube, dry environment, and human activities [18]. In socio-economic sustainability, studies showed that AHSs have been suffering from the impact of economic driver and becoming instable $[19,20]$. Dealing with the issue, researchers proposed that protection measures like constructing a payment for ecosystem services (PES) mechanism [21] and developing multi-value AHSs [22]. In the policy aspect, many local governments have taken measures, including PES for the AHS conservation, tax preferences, fund support, and so forth [23]. 
The national government made a series of management system, for instance, GIAHS and NIAHS management regulation, dynamic monitoring system for GIAHS protection, and the special fund for GIAHS sites [24]. Overall, the GIAHS sites in China have gotten effective protection and become the model in GIAHS protection.

The traditional agricultural production systems and relevant culture are the foundation of Chinese civilization [25]. The CPC Central Committee attaches great importance to the AHS conservation. Documents No. 1 of the CPC Central Committee in 2016, 2017, and 2018 pointed out that "conducting the general survey and protection of agricultural heritage systems", "supporting the protection of important agricultural heritage systems", and "effectively protecting excellent agricultural heritage systems and promoting the rational and appropriate utilization of them", respectively, were all required at national level. The exploration, protection, inheritance, and utilization of AHSs play roles in guiding the sustainable development of agriculture and increasing farmers' employment and inheriting agricultural civilization. This provides an unprecedented opportunity for the protection and development of AHS.

In traditional Chinese culture, all things are dynamic and the system that they are in was kept balanced and stable through continuous changes and circulation. Based on the philosophic thinking, the Chinese ancestors paid attention to building a compound agricultural system consisting of crop farming, forestry, animal husbandry, and fishery using their symbiotic and mutually beneficial relationship in natural areas [26]. These agricultural practices contain profound ecosystem management wisdom and eco-economic thoughts, which are like today's eco-agricultural concepts. In China, natural environment varies greatly from the north to the south. The types of agriculture are diverse. Since the Song Dynasty (A.D. 960-A.D. 1279), the large-scale agriculture under the water ecological environment like paddy field agriculture have surpassed the dry farming in the north and become the most important agricultural type to support the national economy. In the long-term production practice, farmers in the South China have created a large number of aquatic ecological agricultural systems, and developed a series of knowledge and technology of aquatic ecological conservation, which are described in Franklin H. King (1848-1911)'s Farmers of Forty Centuries and Joseph Needham (1900-1995)'s History of Science and Technology in China (Agriculture) written by Francesca Bray. Currently, China has still retained numerous agricultural heritage systems on aquatic-ecological conservation (AHSAEC) through evolving over hundreds or thousands of years. They are precious ecological models in sustainable utilization of local water, soil, climatic, and biological resources.

However, at present, there are few in-depth literatures on this kind of AHS. At the same time, the modern agriculture encounters development bottlenecks in resources, environment, and technology. Agricultural ecological service functions are weakening. The carrying capacity of the environment is declining, but the demand for sustainable development is increasing. Thus, we should re-examine these AHSAECs with a long history, ecological friendliness, rich cultural connotation, and outstanding comprehensive benefits. In this study, we will explore the traditional eco-wisdoms of AHSAECs and analyze their mechanisms for achieving and maintaining the agricultural sustainability. These eco-wisdoms will play an important role in promoting the sustainable development of agriculture, promoting the revitalization of villages, and accelerating the construction of ecological civilization.

\section{Materials and Methods}

In this study, we selected those typical AHSAECs and the typical agricultural production system on aquatic-ecological conservation in history as research objects. Here, "typical" means that they should be well known to the public and have rich written records or a certain scientific research basis, or significant positive effects on the sustainable development of local agricultural industries, economic prosperity, cultural progress, ecological balance, and social stability.

The AHSAEC refers to the AHS that relies on water areas and their derivative ecosystem for production, maintains high biodiversity, provides diverse ecosystem services, and has strong self-adjustment ability to keep its stability and sustainability $[13,15,23]$. They often have a long history of 
development and evolution. Aside from the eight common characteristics (systematicness, adaptability, livingness, dynamics, sustainability, multi-function, endangerment, and strategic significance) of AHSs [27], they also enjoy high output, low investment, labor saving, weak regionality, popularization, and easy replication. These AHSAECs have proved to have strong adaptivity for natural environmental changes, technological innovation, and socio-economic changes. They have important livelihood function for local people. In this study, the ancient books on aquatic ecoagriculture and relevant development history were searched and gained from ancient book database of the national digital library of China, the Complete Works of Chinese Classics in the Imperial Library Wenyuange (文波阁) and Wenjinge (文津阁). The literature on studies of AHSs and aquatic ecoagriculture was obtained from the largest literature database, China National Knowledge Infrastructure (CNKI).

This paper systematically analyses the scientific and technological rationality and cultural adaptability of AHSAECs through interdisciplinary research including history of science and technology, philosophy of science and technology, ecological philosophy, and ecological economics. Various research methods were used in the study: (1) Literature analysis method, including combing and analysis of ancient and modern literature and information; (2) Strengths, Weakness, Opportunities, and Threats (SWOT) analysis, i.e., to analyze the corresponding development situation and response strategies based on the main internal strengths and weaknesses and external opportunities and threats of AHSAECs; (3) induction method, i.e., to extract a certain common attributes and mechanisms from the collection of AHSAECs; and (4) diagram analysis, i.e., to analyze systematically the eco-process and the relationship between ecological factors in AHSAEC ecosystem by relational graph.

\section{Results}

\subsection{Sustainability of Important AHSAECs}

\subsubsection{List of Important AHSAECs}

Since the 21st century, certain AHSAECs have also received the concern and attention of China and even the whole world and have been protected successively as the treasure of Chinese culture. For example, Ministry of Agriculture of China first submit Chinese GIAHS proposal to FAO and was designated the first GIAHS in 2005 and launched China important agricultural heritage system (China-NIAHS) selection in 2012. Until now, in the 91 China-NIAHSs, nine are AHSAECs. Four of the nine have been designated as GIAHS. In order to reveal the functions and value of AHSAECs, this study compiled a catalogue of the nine that have far-reaching international impact and outstanding comprehensive benefits, as shown in Table A1, and explained the main value and function of every GIAHS or China-NIAHS.

\subsubsection{SWOT Analysis of the Sustainability of Important AHSAECs}

According to data from Annexed Table 1, it is shown that China's important AHSAECs have roughly similar eco-economic functions and value, and each has famous local products that can promote the formation of a unique local ecological industry chain. However, the number of AHSAECs is not large and the distribution range is quite limited. Therefore, it is not easy to extend and generalize them according to their traditional models. Due to inherent defects, the AHSAECs exist in many places only as excellent agricultural modes rather than generally applicable ones now. Here, the result of SWOT analysis for important AHSAECs is concentrated as follows in Table 1.

Agricultural production system in AHSAEC sites takes water area as the core; planting rice, mulberry, lotus, and other paddy field crops is the basic agricultural pattern. Meanwhile, aquaculture, livestock breeding, forest and vegetable cultivation, agricultural by-products processing, and other production are developed as extended industries for using production space enough and rising added value; the compound agriculture shows diverse production objects, complex production departments, etc. Compared with the production system in AHS sites, the agriculture with high external inputs has 
a high yield and a better economic benefit. However, the frequent external inputs usually exceed the purifying capacity of agricultural environment for some external materials and lead to environment pollution and unsustainability of agricultural ecosystem. The worsening ecosystem is not able to generate products with high quality $[13,15-17]$. Overall, the AHSs have their own advantages in ecological sustainability but have disadvantages in sustainability of economy and production efficiency.

Table 1. SWOT analysis of important agricultural heritage systems on aquatic-ecological conservation (AHSAECs) in China.

\begin{tabular}{cl}
\hline \multicolumn{1}{c}{ SWOT } & \multicolumn{1}{c}{ Analysis } \\
\hline & $\begin{array}{l}\text { In the agroecosystem, there are few materials and energy inputs } \\
\text { from outside the agricultural system, for example, fertilizers, } \\
\text { pesticides, seedlings, etc. The agriculture presents the features of } \\
\text { few wastes, no pollution, low emissions, and the recycling of } \\
\text { materials and energy. The food chain is complex; the ecosystem } \\
\text { is stable; and the anti-interference ability is strong. Most of them } \\
\text { retain lots of national culture and rich traditional farming } \\
\text { technologies. }\end{array} \quad \begin{array}{l}\text { They mostly exist in the agricultural areas where have relatively } \\
\text { poor physical geographical conditions and low population } \\
\text { density. With urbanization and modernization, agricultural } \\
\text { communities are shrinking, agricultural talents are decreasing, } \\
\text { and traditional agricultural technology, knowledge, and } \\
\text { institutions are also disappearing. }\end{array}$ \\
\hline $\begin{array}{l}\text { The quality of native agricultural products is excellent and } \\
\text { well-known, and the penetration of modern agriculture is } \\
\text { relatively weak, so they are characteristic of special agriculture. } \\
\text { People are keen on the products and tourism there. National } \\
\text { policies also support the protection and development of } \\
\text { Agricultural Heritages. }\end{array}$ \\
$\begin{array}{l}\text { Influenced by modern agricultural technologies and market } \\
\text { economy, the characteristics of traditional agriculture and } \\
\text { Small-scale peasant economy are gradually fading. The } \\
\text { increasing pursuit of scale and output may lead to } \\
\text { homogenization, interruption of traditions and loss of } \\
\text { characteristics. }\end{array}$ \\
\hline
\end{tabular}

\subsection{The Root of Sustainability of AHSAEC}

According to the laws of cultural anthropology and ecological philosophy, the factors affecting the emergence and development of the abovementioned traditional production modes are not only physical geography, ethnic groups, economic basis, and cultural psychology, but also the traditional eco-wisdom of the Chinese nation and local communities. It is found that the sustainability of AHSAEC is rooted in traditional eco-wisdom. Traditional eco-wisdom is also the common attribute of AHSAEC. Therefore, it can be passed down to the present day and become the precious spiritual and technological wealth of the Chinese people. 


\subsubsection{Eco-Wisdom of Adaptive Management}

China's aquaculture originated early [28]. For thousands of years, ancestors accumulated a lot of experiences in adaptive management of fish ponds and other waters. For example, according to Shi Jing (Classic of Poetry), Lingzhao is a pool excavated artificially in the early Western Zhou Dynasty. Fishes were artificially bred in the pool, and the fish survived well [29]. During the Western Zhou Dynasty (c. 11th B.C.-771 B.C.), the people of the Central Plains, especially the ancestors of the upper reaches of the Huaihe River, had been able to better transform the water environment, for example, building and operating large fish ponds, not only for fish farming, but also for fry breeding. This can be verified in the archaeological excavation of Sunzhai Western Zhou Site in Xinyang, Henan Province in 1960. The structure of the fish pond is complex. Half the rectangular large fish pond were separated to be medium-sized fish ponds and then the two medium-sized fish ponds were divided into 10 small fish ponds. The depth of these ponds is different. It is similar to the fish pond in Revered Tao Zhu's Cuidebook to Pisciculture and the modern fish pond in shape and structure, reflecting its scientific and technological rationality [30].

According to Revered Tao Zhu's Guidebook to Pisciculture, the earliest fish culture in China is at the end of the Spring and Autumn Period (770 B.C.-476 B.C.). People built six mu (ancient) pools, built nine islands in the pool, and excavated eight deep trenches; in the deep water area, the water depth was 8 feet (about $1.85 \mathrm{~m}$ today); in the shallow water area outside the trench, the water depth was 2 feet ( $0.462 \mathrm{~m}$ today); carps were bred because they do not prey on the same species, grow rapidly, and are easy to breed and valuable. This is a model of ancient ecological design. Based on the habits of fish, ecological engineering is constructed to enable fish to swim around the islands for food and to live in deep ditches. Shallow water areas are suitable for spawning, hatching, and seedling activities. Deep water areas are conducive to overwintering and avoiding summer heat. This model is appropriate to achieve high and good yields, while reducing the intensity of artificial management.

According to the spatio-temporal characteristics, the Chinese ancestors simulated or reformed the water environment and conducted adaptive management from the biological nature. Their aim was to make all kinds of organisms grow naturally. As a result, the ecological output was abundant, the ecosystem stability was strong, and the win-win of economic and ecological benefits was achieved. From the pre-Qin Dynasty to now, this concept has had a profound influence on the people. For example, in the first year of Xining in the Northern Song Dynasty (1068 A.D.), Guangde Lake in Ningbo, Zhejiang, was ecologically transformed to meet the needs of agricultural irrigation and transportation. Under the natural production mechanism of lake-basin ecosystem, people could also harvest aquatic products, fruits and vegetables, wet plants, and other food. This is the embryonic form of ecological agriculture.

In the Ming Dynasty (1368-1644), the inner pond method was the main method of fish culture. Through long-term practice, people gained a lot of experience on how to coordinate the relationship between the survival of fish and the surrounding environment. For example, Huang Xingzeng (1490-1540), a famous scholar of the Ming Dynasty, pointed out that "the pool should not be too deep, if the pool is deep, the water is cold and the fish is difficult to grow up", "the fish swim day and night, if there are continents and islands around which the fish can swim, the fish will grow up easily", "planting bananas on the bank of the pool can alleviate the lack of oxygen in the pool water by dew drops", "planting neem trees on the bank of the pool can provide food for the fish, because the tree fruits fall into the pond when they are ripe"; "grape shelves on the bank can avoid bird dung"; "planting lotus near the bank of the pond can stop otters"; "the place in the north of the pond should be deepened and fish usually gather the place; in this place, the sunshine is abundant and the fish is easy to grow, and the grasses feeding fish are also rich" [31]. These measures are a good reflection of our traditional ecological agriculture concept and traditional ecological management ideas of aquaculture. To sum up, China has a long ecological agricultural civilization, and most of the ideas and technological models of ecological agriculture are deeply and comprehensively imprinted with the adaptive management concept of "learning from nature" and the systematic and holistic ideas. 


\subsubsection{Eco-Wisdom of Compound Agroecosystem Operation}

In ancient China, the working people not only paid attention to adapting to nature, but also created and inherited a lot of sustainable production modes with scientific and technological rationality under the influence of philosophical ideas such as "to assist the nature of all things" (Lao Tzu, Chapter 64) and "to assist the transforming and nourishing powers of heaven and earth" (The Doctrine of the Mean). They can be reflected in the relevant records of many local chronicles in ancient China, such as the following examples. In the Song Dynasty, the Local Chronicle of Jiatai Kuaiji recorded that "In the south of Kuaiji and Zhuji, Jiangsu Province, people dig ponds to raise fish for their business ... fish mainly are variegated carp, silver carp, carp, grass carp and black carp the ponds were planted with Nelumbo, Euryale, Zizania, Cattail, etc." To carry out ecological planning and ecological construction according to local conditions and to arrange production matters rationally can not only achieve substantial economic benefits, but also maintain the balance of ecosystem and improve its stability, so as to increase the biodiversity of ecological areas, to beautify the ecological environment, and to maintain harmony between nature and man. In the Qing Dynasty (1644-1911), Local Chronicle of Huzhou contains the following words: "Black fish feed on snails; grass carp feed on grass; silver carp feed on organisms from fertile pond water, sometimes fed on dung", "In total, it is suitable that black carps and grass carps constitute $70 \%$, silver carps do $20 \%$ and crucian carps and Chinese breams do $10 \%$ in a pond; all of them can grow well". The mixed cultivation of black carp, grass carp, silver carp, crucian carp, and Chinese bream takes advantage of the differences of their ecological habits such as living water layer, feeding habits, and food intake of fish species. The reasonable match of cultivation density can minimize the intensity of artificial feeding and management, and achieve multi-species health, high quality, and high yield. In the Qing Dynasty, Zhenze County Records recorded that "In the harvest season, there are many spikes, fishes and shrimps in paddy fields"; Wenhu Records Manuscript recorded that "In lake fields, rice is ripe, crucian carp is fat", which are the historical portrayal of fish farming in paddy fields in China. China has a long history of fish farming in paddy fields, ahead of other countries abroad [32]. Rice and fish, two ecosystem elements, are mutually beneficial and complementary, constituting a simple ecological agriculture.

In addition, during the Song, Yuan, Ming, and Qing Dynasties, the mulberry/livestock/fruit/ sugarcane-dike-fish-pond model and other compound agriculture models were created in many places in the north and south of China. These production modes have been explored by people in long-term production experiments. They have remarkable comprehensive benefits and strong empirical rationality. They are simple eco-agricultural modes suitable for the traditional small-scale peasant economy. In the process of people's follow-up learning, imitating, and adapting to local conditions, these ecological agricultural models have been inherited and continuously refined. At the same time, Chinese (simple) ecological agricultural ideas and traditions such as "learning from nature" have been inherited and developed.

During the Ming and Qing Dynasties, with the deepening of people's understanding in natural things and the rapid development of traditional agricultural technology, China's agricultural production level had been unprecedentedly improved. Meanwhile, on the basis of the traditional ecological agriculture models, people have developed the compound agricultural production models. These production models can release people's ecological design potential and improve the production efficiency of the ecosystem to a large extent. Thus, they also gave birth to many ideas and practices of composite agroecosystem management with unprecedented benefits. For example, in the Ming Dynasty, the Agricultural Administration Complete Book contained "Making sheep pens on the banks of ponds, raising sheep in them, sweeping their dung into the ponds every morning to feed grass carps, whereafter the grass carp dung can feed silver carps; in this way, the workload of preparing grass carp forage can be reduced"; that is, to build sheepfolds on the fish pond and cultivate grass carps and silver carps in the fish pond. The composition of the food chain is: Grass feeding sheep $\rightarrow$ sheep dung feeding grass carps $\rightarrow$ grass carp dung feeding silver carps. The Qing Dynasty's Changzhao He Zhi Manuscript records that "the lowest depression areas are dug into pools, and the mud from the pools 
are piled around pools to make dikes for farming; the annual income can reach three times that of the plain areas. There are hundreds of such ponds, all for fish farming. On the top of the pond, we set up wooden cages and barns to raise chickens and pigs. Chicken manure and pig manure were eaten by fish in the pond, and the fish grew fat more easily. Plum, peach, and other fruit trees are planted on the dikes. In the periphery of the ponds, Zizania, Heleocharis, Trapa, and Euryale are planted. Vegetables can be grown all year round on plots that can be divided into borders. These crops yield a lot. At the same time, it also attracts birds, insects, and other organisms, which are captured and brought to the market for sale, and the income is quite large. The Supplement to Agricultural Books of the Qing Dynasty recorded that "Digging ponds to raise aquatic animals, thickening pond foundations to grow mulberry and bamboo, planting grain crops in paddy fields, planting fruit trees in empty areas, building shed to keep livestock and poultry". The above examples are similar. Aquaculture, livestock breeding, and other agricultural production departments are closely integrated in spatial arrangement and material utilization, so that the material and energy in the ecosystem can be fully utilized for a high ecological conversion rate and ecosystem output capacity. These models are good models for balancing the internal elements of the composite agroecosystem and achieving excellent operation. They are also good reference models for the development of modern eco-agriculture and multi-functional agriculture. They are also the precursors and prototypes of AHSAECs, and remarkably, AHSAECs and them contain similar eco-wisdom about sustainable agricultural management.

\subsection{Eco-Wisdom of Traditional Ecoagriculture Model}

In the course of development for approximately 2000 years, China's simple traditional ecological agriculture has been enriched in connotation and innovated in technology, which gradually formed some models in the Ming and Qing Dynasties. With industrial structures covering farming, forestry, animal husbandry, sideline, and aquatic industries, these models have rich outputs, strong stability, high comprehensive benefits, and far-reaching impact, so they can be called multi-industry compound ecoagriculture model [33]. These models not only possess higher productivity and larger ecological functions, but also show prominent economic and social functions [34]. These models contain the traditional eco-wisdom, which is helpful to promote regional agriculture to achieve sustainable development.

\subsubsection{Example of Traditional Ecoagriculture Model}

As mentioned above, Changzhao He Zhi Manuscript of Qing Dynasty describes a typical example of traditional ecoagriculture model in Taihu Lake area of Ming Dynasty, which can be called "Taihu Lake multi-industry compound ecoagriculture model". Detailed records of this model can also be found in the Ming Dynasty's Literary Notes of Jie An. The records of the two books (the former was first published in 1597 and the latter in 1904) are roughly the same, which reflects that the agriculture mode had lasted for at least 300 years and had strong stability. According to the principles of food chain, multi-level utilization of matter and energy in ecology, and related principles of industrial ecology and circular economy, the eco-process and ecological relationship among key elements in the eco-economic system was analyzed, as shown in Figure 1.

The model emerged and flourished in the lake-depression area of southern Jiangsu in the Ming and Qing Dynasties. It fully utilized all kinds of natural resources in the area and closely connected the production links to each other to constitute a large circular agricultural eco-economic system.

The system takes the depression as a unit, digs the water depression deep to construct the pond, uses the excavated soil to raise the land around the fish pond, and assarted the land for cultivation. As the pond mud greatly improves the fertility of these farmlands, the yield per unit area of the farmland is three times that of the ordinary farmland. All ponds are used for fish farming. Pigpens are built over the ponds and henhouses are built over the pigpens. When the chickens are raised, the feed scraps and feces fall into the piggery as feedstuffs to be ate by the pigs. The produced waste during the pig cultivation falls into the fishpond, which can improve the fertility of the pond 
water, increase eatables for the fish, and improve the growth rate of the fish. Multiple species of fruit trees are planted on the edge of the farmland. Aquatic plants such as Zizania latifolia, Chinese water chestnut, and Sagittaria trifolia are planted in the large and small water depressions (puddles). Seasonal vegetables are successively planted in the dry land plots all year round. The harvest of fruits, aquatic plant products, and vegetables is substantial per year. Most products from crops, fruit trees, vegetables, and aquatic plants can be used as feedstuffs for chickens and pigs. The litters produced during the growth of these plants and the runoff nutrients derived from precipitation and water flow and the leaching nutrients from plants are largely and gradually converging with the water to the fishpond and puddles, continuously supplying the nutrient of aquatic organisms. Meanwhile, as fertilizer, pond mud will be gradually dug out and applied to all kinds of planting plots. In addition, the system can also produce firewood, economic insects, and other products. All factors make the eco-economic system with high stability, rich output, high yield, and high efficiency.

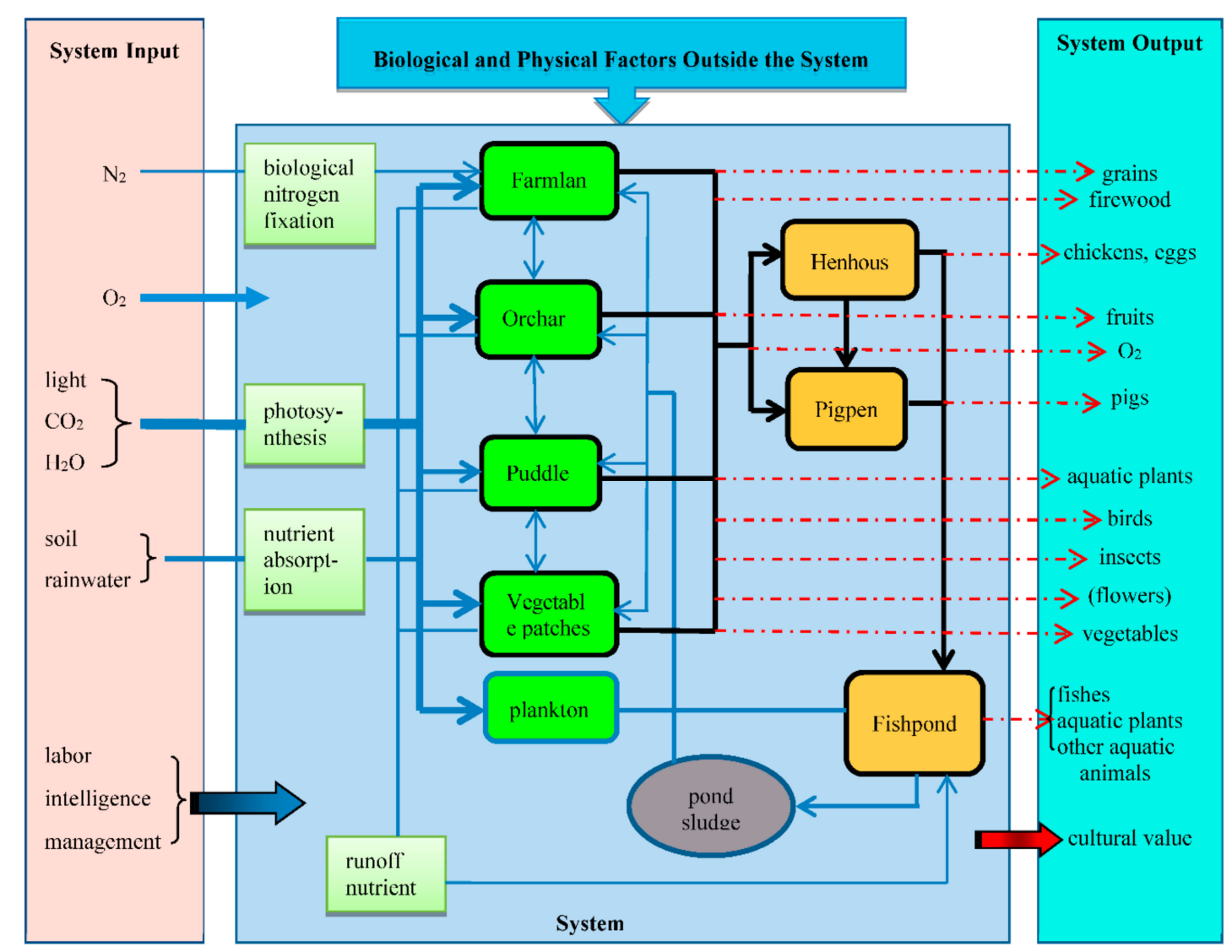

Figure 1. Eco-process of Taihu Lake multi-industry compound ecoagriculture model.

\subsubsection{Analysis of Eco-Wisdom Related}

The system is comprised of seven parts: Fishpond, farmland, orchard, puddles, vegetable patches, chicken house, and pig house. The production units such as fish, fields, fruit trees, vegetables, chickens, and pigs are also an integral system. Therefore, the system is a semi-artificial organic ecosystem composed of various subsystems with distinct levels of land-water interaction, as shown in Figure 1. The basic components of the system are plants, animals, microorganisms, and inorganic environment. Through the adjustment and transformation by human labor, the components are closely linked and inseparable. These connections are mainly those of material flow, energy flow, information flow (referring to the feedback and self-regulation process of each part), and value flow. The fruit trees on the edge of the farmland play a role in preventing soil erosion. Both the excrement from chickens and pigs and the residue feed fallen into the fishpond can raise numerous aquatic plankton. These plankton 
and aquatic plants can also be used for fish consumption. According to the niche principle, this kind of multielement compound ecosystem model arranges all kinds of agricultural (including aquaculture) species with high economic value in different spaces of lake-depression area. According to the principle of food chain and the principle of multi-level utilization of material and energy, it connects planting with livestock breeding and aquaculture organically, and realizes large-scale farming. Efficient energy flow, material circulation, information transmission, and value increment succeed in the compound eco-economic system.

The industrial system of the eco-agricultural system consists of aquaculture, planting, and poultry and livestock farming in Taihu Lake areas (Figure 2). It realizes the orderly connection of farming, forestry, animal husbandry, sideline, and aquaculture. It is a relatively perfect and mature mode of large-scale agricultural production. There are three key links in the model, i.e., (1) the harvest of planting industry provides feed for poultry and livestock breeding; (2) the waste produced by livestock and poultry breeding provides some baits and water fertilizer for aquaculture industry; and (3) the sludge formed at the bottom of fish pond is transferred to the land as fertilizer by dredging. The utilization of pond sludge reflects the long tradition of organic agriculture and circular economy in ancient China and the ecological wisdom of systematic thinking.

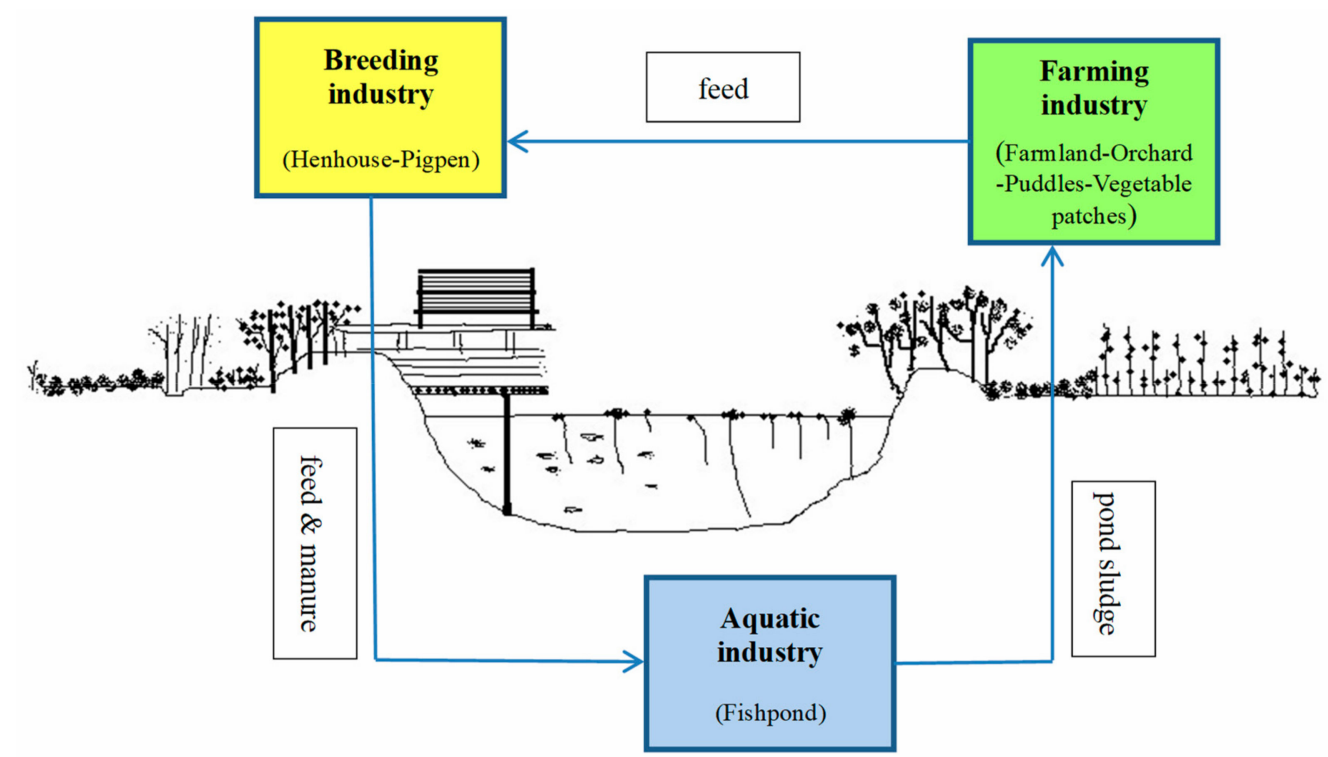

Figure 2. Basic structure of Taihu Lake multi-industry compound ecoagriculture model.

During the operation of fishponds, the surplus food debris is deposited at the bottom of the ponds along with biological excreta due to the continuous feeding, and nutrients in the whole large agricultural system converge to the lower terrain by gravity, which causes the pond mud to have rich nutrients, which are several times more than other natural soils. Therefore, pond sludge is a good fertilizer. Throughout history, the use of pond sludge as fertilizer for various crops is a common practice of farmers in south China. In the majority of traditional agricultural production modes, pond sludge is regularly excavated and applied to the roots of all kinds of crops, which not only reduces bottom silt of pools and prevents water eutrophication, but also transfers nutrients from ponds at the lowest position of the ecosystem to the upper position of the ecosystem and moves into the agricultural ecosystem, so that they can be obtained and utilized again. 
Similar to the preceding example, many traditional eco-agriculture models have transformed some nutrients into various and high-quality ecological products through promoting the continuous or multiple cycles of nutrients in the compound ecosystem, and at the same time created the value of ecosystem services such as cultural services and emotional adjustment. This is similar to the ecological functions and values of the important AHSAEC in China mentioned above. Perhaps the latter is the result of the former's succession along with regional adaptation and evolution, and is formed and evolved because of the former's influence in some aspects.

Through comparison, it is found that the traditional ecological agriculture models in ancient China is different from the main AHSAEC in modern China, but they contain similar rich and profound traditional eco-wisdom. It is necessary and urgent to conduct in-depth mining, comprehensive research, effective inheritance, and protective development of the ecological wisdom.

\section{Discussion}

Eco-wisdom of traditional agriculture system has been a concern and stressed since GIAHS programme initiated by FAO and in 2002, which was proposed on the background of wide negative impacts from the modern petroleum agriculture. When the GIAHS concept was put forward, lots of countries and international organizations, like the Global Environment Facility, responded and participated in the project. In 2014, GIAHS project was listed into regular budget of FAO and GIAHS designation and conservation became a routine work. In this year, the high-level training on GIAHS under FAO-China South-South Cooperation Capacity Building Programme began to be held in China to help the developing countries in the world protect traditional ecoagriculture. Up to now, the GIAHS training programme has been held for six times and more than five countries accept the training. Until 11 November 2019, there were 57 GIAHSs distributed in 21 countries, which are over five continents of the world. They can be classified as crop farming (including dry crop farming and paddy field farming), forestry, animal husbandry, fishery, and the compound systems like agroforestry [14]. Currently, the GIAHS conservation and monitoring work are also implemented for protecting the traditional agricultural system and eco-wisdom. Europe and East Asia also built a regional GIAHS alliance to promote the traditional agricultural wisdom conservation [22,23,35]. In sum, the sustainability of traditional agriculture and the eco-wisdom it contained has been paid more and more attention by international society.

In China, AHS conservation also has become an important work item of national government. In January 2017, the General Office of CPC Central Committee and the General Office of the State Council of China issued the Opinions on Implementing the Project of Inheritance and Development of Chinese Traditional Culture, which calls for "doing a good job in the protection of agricultural heritages". In September 2017, the abovementioned institutions issued Opinions on Innovating Systems and Mechanisms to Promote Green Agricultural Development, which calls for "exploring regional agricultural recycling mechanism, implementing the overall planning of grain crops, cash crops and feed crops, combining cultivation and aquaculture with processing industry, and integrating planting, forestry, animal husbandry, side-line production and aquaculture" and "expanding the multiple functions of agriculture to create an rusticity ecosystem featuring combination of farming and breeding, ecological cycle and beautiful environment". Technical Guidelines for Green Agricultural Development (2018-2030), promulgated by the Ministry of Agriculture and Rural Affairs of China in July 2018, pointed out that "to promote green agricultural production, farming and breeding cycle, ecological conservation and restoration", "to promote the establishment of a new pattern of eco-agriculture which matches agricultural productivity with carrying capacity of resources and environment, so as to make agriculture Beautiful China's ecological support", "to adhere to the road of green agricultural development, to achieve environmental friendliness and ecological conservation". In January 2019, the Office of the Rural Work Leading Group of CPC Central Committee and the Ministry of Agriculture and Rural Affairs issued the Opinions on Implementing the Agricultural and Rural Work in 2019, which put forward "to study and formulate the guidelines for the protection and inheritance of Nationally Important Agricultural Heritage Systems of China". 
According to the available literature, Chinese AHSAECs have a long history and a great many models. Their function and values are an important reference to modern agricultural sustainable development. For the preservation and continuation of China's excellent traditional culture, it is necessary to carry out in-depth discussion, deep thinking, lively use, overall protection, responsible inheritance and educational promotion of eco-wisdom on water ecological conservation.

Sustainability of Chinese AHSAECs is attributed to two key factors: Sustainable mechanism of AHSAECs and how to inherit and develop the AHSAECs.

At first, under the influence of the ecological philosophy "Nature and Man in One", the traditional aquatic industry in China paid attention to following the natural law and maintaining harmony between man and nature in every detail of production. With the continuous development of compound agricultural production, the practice of simple ecological agriculture and circular agriculture had gradually come into being in the process of mutual assistance and mutual inheritance (in terms of material and energy utilization) between aquatic production and other types of production. With the passage of time, these eco-agricultural practices have gradually transformed into some intensive and efficient eco-agricultural models featuring rich connotation and strong circulation of internal factors. Behind these models lies the ecological wisdom of learning from nature and adapting to local conditions.

As an important part of the traditional aquatic industry in China, traditional aquaculture is a productive sector that effectively utilizes suitable waters to breed aquatic economic animals and plants, speeds up the process of material circulation and energy flow in the aquatic ecosystem, and further promotes the value enhancement and intensive utilization of natural resources. In the long-term production practice, people have accumulated rich experience in fish farming, created a systematic culture technology, and explored some breeding models with good comprehensive benefits and wide adaptability. The emergence and continuous development of aquaculture industry indicates the continuous enhancement of human impact and control ability on aquatic ecosystem. However, although marine, offshore, terrestrial, and other aquatic ecosystems have strong self-regulation and feedback balance capabilities, scientific researches and recent evidences show that they are in fact extremely fragile systems. Therefore, in the process of aquaculture development, the key to the sustainable development of aquaculture is to deal with the relationship between resource utilization, environment modification, and the balance maintenance of aquatic ecosystem.

Under the guidance of traditional ecological wisdom such as "learning from nature" and "Heaven and nature united", our ancestors carried out ecological planning and moderate exploitation of natural or artificial waters in accordance with time, place, and material conditions from the perspective of the macro-agricultural-technological-socio-economic system as a whole. They optimized the waters ecology through the ecological engineering methods, dredged the channel of material and energy flow in the ecosystems, bred and conserved the local fine aquatic species, and managed the aquaculture objects adaptively, gradually developing the "natural" aquatic industry at the ecosystem level. Later, with the overall progress of traditional agricultural production technology, the interaction between farming, forestry, animal husbandry, by-products, and aquatic industries had become more and more intense. Each industry made more use of products or wastes from other industries in terms of production input and raw material sources, thus making the correlation between industries stronger. The traditional eco-agriculture models with recycling and regenerative production mechanism were established. According to the number of industrial branches integrated, they could be divided into monistic, dualistic, and pluralistic eco-agriculture models. The development of aquaculture makes it possible to integrate the water and land ecosystems into an organic whole in agricultural production. Therefore, aquaculture is an important link to form the traditional ecoagriculture models. The traditional ecological agriculture patterns related to aquaculture are as follows: (1) The monistic mode, also known as ecological aquaculture mode, is mainly the polyculture technology of multi-species domestic fishes, which has a wide range of applications; (2) the dualistic compound modes are mainly the paddy field breeding mode, the pond-dike farming mode, the fish-livestock/poultry raising mode (such as 
grass-pig-fish mode), etc., which have the characteristics of flexibility, variety, simple operation, weak demand for human management, and high comprehensive benefits; (3) the pluralistic compound mode is mainly the multi-industry compound eco-agriculture mode of Taihu Lake, which requires high environmental conditions, has high demand for capital investment, human management, comprehensive skills of workers, and is suitable for households with large labor force and orderly organization. These are the prototypes or predecessors of modern AHSAECs. Ancient and modern models contain the same or similar ecological wisdom and cultural genes.

Second, with the increasing burden of resources, environment, and population on the world's agricultural development, sustainable agriculture and ecological agriculture are the only way for future agricultural development and progress, especially in developing countries such as China. The multifunction and unique value of AHSAECs is the best proof. China has a long tradition of simple eco-agriculture and a deep and excellent foundation of eco-agriculture. Since entering modern society, on the basis of inheriting tradition and preserving agricultural heritage systems, people have developed or created some new models, such as "bay fish-shrimp-shellfish-algae co-culture model", "forest-vegetable (grass)-livestock (poultry)-biogas-fish compound system", "fruit-vegetable-poultry-fish-mussel compound system", "forest-rice-duck-fish compound ecoagriculture model", "forest-fruit-poultry-biogas-fish compound ecoagriculture model", "forest-fish-duck-bird stereoscopic multi-layer ecoagriculture model", etc. In the modern ecological models, the sludge produced by regular dredging of fish ponds is still used to provide high-quality organic fertilizer for the planting industry. The construction of yard biogas digesters provides a new way for the reuse of many kinds of wastes produced in the process of ecosystem production. Through the harmless treatment and resource utilization of agricultural wastes, animal husbandry, planting, and aquaculture are linked, thus constituting an ecological system of material recycling and energy multi-level circulation and promoting the sustainable utilization of water resources and environment, which is the ecological wisdom throughout ancient and modern times.

With the rapid development of the market economy, most of the modern compound ecological agriculture modes have turned to intensive production patterns, which depend on the overall function of the regional agricultural eco-economic system. Generally speaking, the planning and construction of regional large-scale agricultural eco-economic system is the basis of creating and operating eco-agriculture system. The development of eco-agriculture in AHSAEC sites is also promoting the interaction between agricultural ecosystems and further promoting the formation of regional large-scale agricultural eco-economic systems. However, the traditional eco-agriculture modes, such as agricultural heritage systems, are mostly dependent on the agricultural social environment in which the small-scale peasant economy is the main economic form [35]. In most places, traditional production experience and eco-wisdom are being lost, and they have their limitations in the modern social environment. Because of their complex internal relations, macro-broad thinking, and experience nature, once they leave their original environment, they may be ineffective. Therefore, when we inherit and develop the essence of traditional ecoagriculture, on the one hand, we should try our best to catch up with the loss of traditional knowledge. On the other hand, we need to use modern science and technology to reveal its basic principles and the relationship between internal factors, test its effect through practical operation, and gradually promote it after adaptive transformation and upgrading. In the current situation of rapid economic, technological, and social development, massive loss of rural labor force and increasing endangerment of traditional rural communities, it is urgent to take measures as soon as possible to rescue, save, and preserve the fine traditional eco-agriculture, for example, establishing living museums, ecological museums, and a traditions and heritage inheritor system to realize the productive protection of AHSAECs for inheriting and developing eco-wisdom. 


\section{Conclusions}

With the increasing pressure from the population, resources, and environment, sustainability of agriculture is stressed by international society and lots of countries, especially for those countries in arid and semiarid climatic zones. This study mainly focuses on sustainability of the AHSAECs and analyzes their sustainable inheritance mechanism. Different from most other AHSs, AHSAECs are usually a multiple compound ecosystem which refers to mountains, water areas, forests, farmland, and grassland, etc. Based on water ecosystem and taking aquaculture as the core, AHSAECs usually cover two and more sections of plantation, forestry, animal husbandry, and fishery. Each AHSAECs are a circular system that maximize the value of the compound ecosystem through multi-function development and water circulation and waste reuse. AHSAECs can be inherited and developed to now, there are two reasons: first is the sustainability of AHSAECs created under the guidance of the ecological philosophy of Chinese traditional culture such as "learning from nature", "to assist the nature of all things", and "to assist the transforming and nourishing powers of nature"; second is the adaptive management that farmers continually absorb advanced agricultural technologies and the constructed stable inheritance mechanism in the traditional agricultural society. In AHSAEC conservation, the sustainable culture inheritance should be given more attention because of its key role in sustainability of AHSAECs. The traditional eco-wisdom, for example, ecological thought, ecological knowledge, and ecological technologies, can be protected through ecological museum construction. Provided they are protected well, the management system on AHSAECs can be implemented effectively and sustainability of agriculture in AHSAEC sites can be ensured.

Author Contributions: The authors undertook different work for this paper. Q.T. and Y.Z. provided direction to the research work and participated in the research. M.L. and L.L. did the literature review and collected relevant data and M.L. wrote the manuscript. M.X. searched and collected data on GIAHS and China NIAHS; L.H. searched and collected literature and evidence. Y.Z. and M.X. revised the paper. All authors have read and approved the final manuscript. L.H. collected and analyzed the literature this paper needs. All authors have read and agreed to the published version of the manuscript.

Funding: This research was funded by The Humanities and Social Sciences Research Project of the Chinese Ministry of Education in 2017, grant number 17YJCZH090 and The Humanities and Social Sciences Research Project of Henan Education Department, China in 2018, grant number 2018-ZZJH-431.

Acknowledgments: We appreciate the productive suggestion from editors and anonymous reviewers and would like to give our thanks to them.

Conflicts of Interest: The authors declare no conflict of interest. 


\section{Appendix A}

Table A1. Catalogue of important AHSAEC in China $[14,25,36]$.

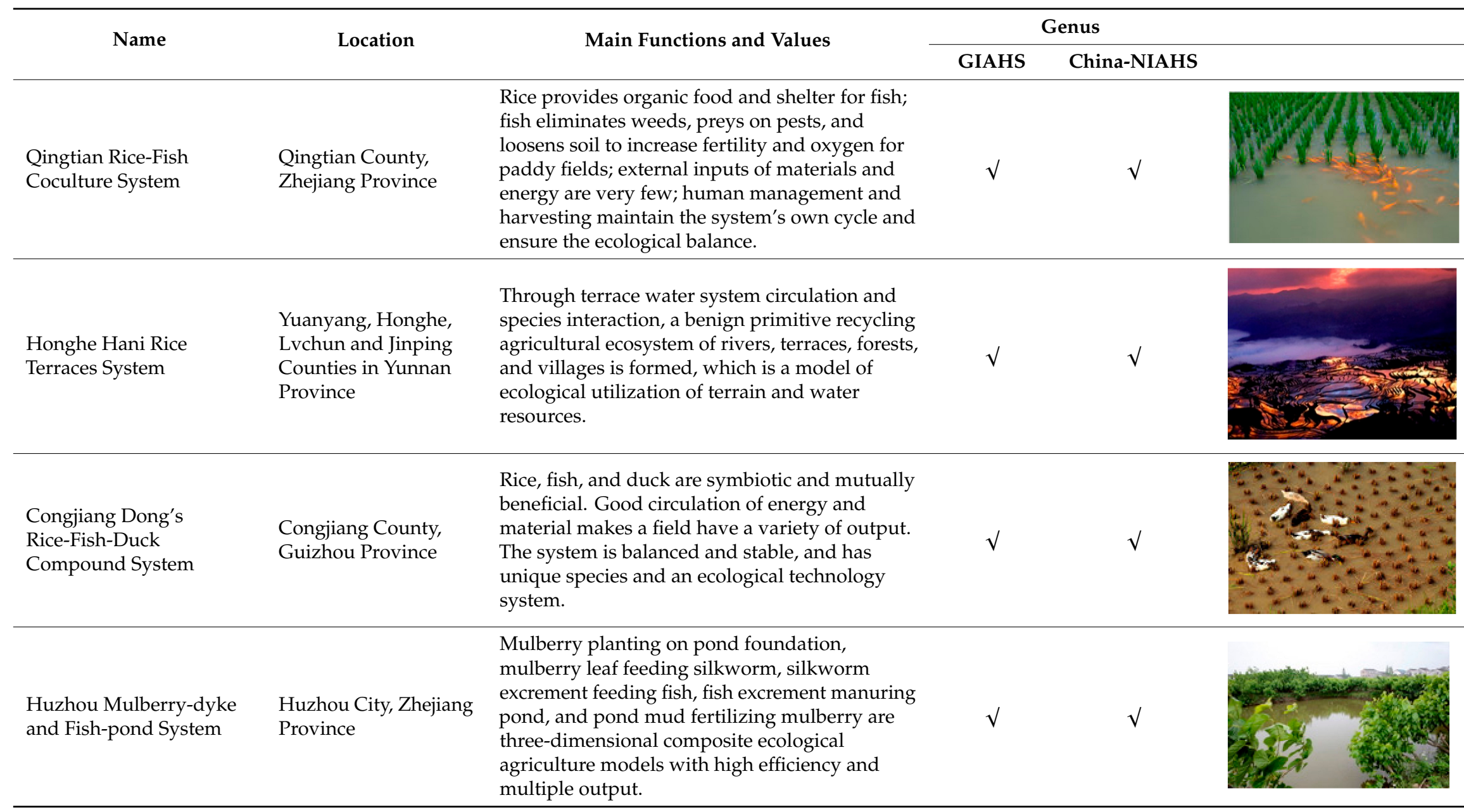


Table A1. Cont.

\begin{tabular}{|c|c|c|c|c|c|}
\hline \multirow{2}{*}{ Name } & \multirow{2}{*}{ Location } & \multirow{2}{*}{ Main Functions and Values } & \multicolumn{2}{|c|}{ Genus } & \\
\hline & & & GIAHS & China-NIAHS & \\
\hline $\begin{array}{l}\text { Xinghua Duotian } \\
\text { Agrosystem }\end{array}$ & $\begin{array}{l}\text { Xinghua City, Jiangsu } \\
\text { Province }\end{array}$ & $\begin{array}{l}\text { It is a stable and efficient wetland eco-agricultural } \\
\text { system to construct a large number of orderly } \\
\text { partitioned plots in large swamps and depressions, } \\
\text { to plant on the plots, to develop aquaculture among } \\
\text { the plots, and to carry out agro-forestry-fishery } \\
\text { production. }\end{array}$ & $\sqrt{ }$ & $\sqrt{ }$ & 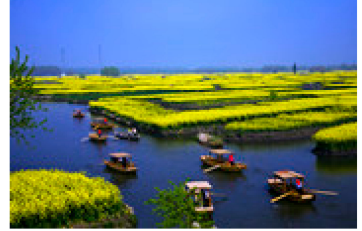 \\
\hline $\begin{array}{l}\text { Xiuning Fish Culture } \\
\text { System in Flowing Water } \\
\text { of Mountain Springs }\end{array}$ & $\begin{array}{l}\text { Xiuning County, } \\
\text { Anhui Province }\end{array}$ & $\begin{array}{l}\text { Through a good flowing water system, a composite } \\
\text { agroecosystem composed of forest-spring-pond } \\
\text { fish-village-river unity is formed to realize } \\
\text { multi-level utilization of material and energy. }\end{array}$ & & $\sqrt{ }$ & 6 \\
\hline $\begin{array}{l}\text { Gaoyou Lakes and } \\
\text { Wetlands Agrosystem }\end{array}$ & $\begin{array}{l}\text { Gaoyou City, Jiangsu } \\
\text { Province }\end{array}$ & $\begin{array}{l}\text { It is a three-dimensional agro-ecosystem combining } \\
\text { fish, duck, crab, and rice cultivation to implement } \\
\text { rice-duck co-cultivation on land and water-land } \\
\text { interlaced space in lake area and fish-crab-duck } \\
\text { co-cultivation in lake water space. }\end{array}$ & & $\sqrt{ }$ & \\
\hline $\begin{array}{l}\text { Deqing Traditional } \\
\text { Culture and Utilization } \\
\text { System of Freshwater } \\
\text { Pearls }\end{array}$ & $\begin{array}{l}\text { Deqing County, } \\
\text { Zhejiang Province }\end{array}$ & $\begin{array}{l}\text { It makes the pearl mussel form complex ecological } \\
\text { relationship with other species, so as to achieve the } \\
\text { ecological balance of water area. At the same time, } \\
\text { the rational use of water and soil resources, through } \\
\text { mulberry planting, rice (wheat) planting, animal } \\
\text { husbandry and fish farming complement each other, } \\
\text { constitute the interdependent } \\
\text { grain-mulberry-fish-livestock system and ecological } \\
\text { agricultural landscape including mulberry fields, } \\
\text { paddy fields and ponds. }\end{array}$ & & $\sqrt{ }$ & \\
\hline $\begin{array}{l}\text { Guangchang Traditional } \\
\text { Lotus Farming System }\end{array}$ & $\begin{array}{l}\text { Guangchang County, } \\
\text { Jiangxi Province }\end{array}$ & $\begin{array}{l}\text { By means of white lotus-Alisma rotation, white } \\
\text { lotus-rice rotation and lotus-fish co-culture, the full } \\
\text { utilization of biological resources in water area has } \\
\text { been realized, and the ecological balance and } \\
\text { high-efficiency output have been achieved. }\end{array}$ & & $\sqrt{ }$ & \\
\hline
\end{tabular}

Note: the photos were gotten from the reference [36]. 


\section{References}

1. Steffen, W.; Broadgate, W.; Deutsch, L.; Gaffney, O.; Ludwig, C. The trajectory of the anthropocene: The great acceleration. Anthropocene Rev. 2015, 2, 81-98. [CrossRef]

2. Kuyper, T.W.; Struik, P.C. Epilogue: Global food security, rhetoric, and the sustainable intensification debate. Curr. Opin. Environ. Sustain. 2014, 8, 71-79. [CrossRef]

3. Rockström, J.; Williams, J.; Daily, G.; Noble, A.; Matthews, N.; Gordon, L.; Wetterstrand, H.; DeClerck, F.; Shah, M.; Steduto, P.; et al. Sustainable intensification of agriculture for human prosperity and global sustainability. Ambio 2017, 46, 4-17. [CrossRef] [PubMed]

4. UN. Transforming Our World: The 2030 Agenda for Sustainable Development. Available online: https: //sustainabledevelopment.un.org/post2015/transformingourworld (accessed on 13 November 2019).

5. FAO. Tracking Progress on Food and Agriculture-Related SDG Indicators: A Report on the Indicators under FAO Custodianship. Available online: http://www.fao.org/sdg-progress-report/en/ (accessed on 13 November 2019).

6. Piao, S.; Ciais, P.; Huang, Y.; Shen, Z.; Peng, S.; Li, J.; Zhou, L.; Liu, H.; Ma, Y.; Ding, Y.; et al. The impacts of climate change on water resources and agriculture in China. Nature 2010, 467, 43-51. [CrossRef]

7. McCouch, S.; Baute, G.J.; Bradeen, J.; Bramel, P.; Bretting, P.K.; Buckler, E.; Burke, J.M.; Charest, D.; Cloutier, S.; Cole, G.; et al. Feeding the future. Nature 2013, 499, 23-24. [CrossRef]

8. Zhang, F.; Chen, X.; Vitousek, P. Chinese agriculture: An experiment for the world. Nature 2013, 497, 33-35. [CrossRef]

9. Petherick, A. Agriculture: Drought in China. Nat. Clim. Chang. 2011, 1, 293. [CrossRef]

10. Seufert, V.; Ramankutty, N.; Foley, J.A. Comparing the yields of organic and conventional agriculture. Nature 2012, 485, 229-232. [CrossRef]

11. Jiao, W.; Fuller, A.M.; Xu, S.; Min, Q.; Wu, M. Socio-ecological adaptation of agricultural heritage systems in modern China: Three cases in Qingtian County, Zhejiang Province. Sustainability 2016, 8, 1260. [CrossRef]

12. Li, W. Strategic Research on the Conservation and Development of China's Important Agricultural Heritage Systems; Science Press: Beijing, China, 2016; pp. 4-6. (In Chinese)

13. Li, W. Agro-Ecological Farming Systems in China; Parthenon Publishing Group: Paris, France, 2001; pp. $2-4$.

14. FAO. GIAHS around the World. Available online: http://www.fao.org/giahs/giahsaroundtheworld/en/ (accessed on 24 September 2019).

15. Xie, J.; Hu, L.; Tang, J.; Wu, X.; Li, N.; Yuan, Y.; Yang, H.; Zhang, J.; Luo, S.; Chen, X. Ecological mechanisms underlying the sustainability of the agricultural heritage rice-fish coculture system. Proc. Natl. Acad. Sci. USA 2011, 108, 1381-1387. [CrossRef]

16. Zhang, D.; Cheng, S.; Yang, H.; He, L.; Jiao, W.; Liu, S.; Min, Q. Ecological control effects on pest, pathogen and weed of multiple species coexistence in paddy fields in traditional agricultural regions. Resour. Sci. 2011, 33, 1032-1037.

17. Sun, Y.; Zhou, H.; Zhang, L.; Min, Q.; Yin, W. Adapting to droughts in Yuanyang Terrace of SW China: Insight from disaster risk reduction. Mitig. Adapt. Strateg. Glob. Chang. 2013, 18, 759-771. [CrossRef]

18. Zhang, Y.; Liu, M.; Min, Q.; Lun, F.; Zhang, C.-Q. Environmental adaptability and service functions of Chinese jujube forest ecosystem in Jiaxian County, Shanxi Province. Arid Zone Res. 2014, 31, 416-423. (In Chinese)

19. Yang, H.; Lv, Y.; Jiao, W.; Min, Q. Analysis on driving factors of land use change in traditional agricultural regions: An empirical study based on household behaviors. Resour. Sci. 2010, 32, 1050-1056. (In Chinese)

20. Zhang, Y.; Min, Q.; Zhang, C.; He, L.; Zhang, S.; Yang, L.; Tian, M.; Xiong, Y. Traditional culture as an important power for maintaining agricultural landscapes in cultural heritage sites: A case study of the Hani terraces. J. Cult. Herit. 2017, 25, 170-179. [CrossRef]

21. Liu, M.; Xiong, Y.; Yuan, Z.; Min, Q.-W.; Sun, Y.-h.; Fuller, A.M. Standards of ecological compensation for traditional eco-agriculture: Taking rice-fish system in Hani terrace as an example. J. Mt. Sci. 2014, 11, 1049-1059. [CrossRef]

22. Zhang, Y.; He, L.; Li, X.; Zhang, C.; Qian, C.; Li, J.; Zhang, A. Why are the Longi Terraces in Southwest China maintained well? A conservation mechanism for agricultural landscapes based on agricultural multi-functions developed by multi-stakeholders. Land Use Policy 2019, 85, 42-51. [CrossRef]

23. Min, Q.; Zhang, Y.; Jiao, W.; Sun, X. Responding to common questions on the conservation of agricultural heritage systems in China. J. Geogr. Sci. 2016, 26, 969-982. [CrossRef] 
24. Jiao, W.; Min, Q. Reviewing the Progress in the Identification, Conservation and Management of China-Nationally Important Agricultural Heritage Systems (China-NIAHS). Sustainability 2017, 9, 1698. [CrossRef]

25. Ministry of Agriculture Announces the Results of the 2016 National Survey of Agricultural Heritage Systems. Available online: http://www.gov.cn/xinwen/2016-12/13/content_5147058.htm (accessed on 10 October 2019).

26. Yang, T.; Huang, L. The simple sustainable development system view of ancient China's agriculture embodied in Qimin Yaoshu. Sci. Technol. Dialectics 1995, 15, 12-16. (In Chinese)

27. Min, Q. The characteristics and conservation of agricultural heritage systems. World Environ. 2011, 1, 18-19. (In Chinese)

28. Li, M.; Jin, X.; Tang, Q. Policies, regulations, and eco-ethical wisdom relating to ancient Chinese fisheries. J. Agric. Environ. Ethics 2012, 25, 33-54.

29. Chen, S. A poem praising the construction of Lingtai by the Zhou Dynasty and the people's happiness. J. Humanit. 1986, 69. (In Chinese)

30. Huang, K. On the origin of artificial fish culture in China from the Western Zhou Site at Sunzhai in Xinyang, Henan Province. Anc. Mod. Agric. 1994, 67-72. (In Chinese)

31. Editorial Department of Xinwenfeng Publishing House. New Edition of Series Integration; Xinwenfeng Publishing House: Taipei, China, 2008; Volume 74, p. 571. (In Chinese)

32. Xiang, A. Doubts about the origin of fish culture in rice fields in the Eastern Han Dynasty. Agric. Hist. China 1996, 79-86. (In Chinese)

33. Zhu, G.; Lu, Y.; Li, Q. Inheritance and development of traditional ecological farming systems in Lake Taihu Area under background of modernization: From perspective of agricultural heritage. J. Nanjing Agric. Univ. 2015, 15, 109-116. (In Chinese)

34. Li, B. Agricultural Development in the South of the Yangtze River; Shanghai Ancient Books Publishing House: Shanghai, China, 2007; p. 73. (In Chinese)

35. Zhang, Y.; Li, X.; Min, Q. How to balance the relationship between conservation of Important Agricultural Heritage Systems (IAHS) and socio-economic development? A theoretical framework of sustainable industrial integration development. J. Clean. Prod. 2018, 204, 553-563. [CrossRef]

36. Record of China Nationally Important Agricultural Heritage Systems. Available online: http://www.moa. gov.cn/ztzl/zywhycsl/ (accessed on 3 December 2019).

(C) 2019 by the authors. Licensee MDPI, Basel, Switzerland. This article is an open access article distributed under the terms and conditions of the Creative Commons Attribution (CC BY) license (http://creativecommons.org/licenses/by/4.0/). 